\title{
IMPLEMENTASI MANAJEMEN BANDWIDTH PADA JARINGAN KOMPUTER DENGAN ROUTER MIKROTIK
}

\author{
Fahlepi Roma Doni \\ Universitas Bina Sarana Informatika \\ fahlepi.fro@bsi.ac.id
}

\begin{abstract}
As the development of information technology today, the development of computer networks also develops, with the rank and application of bandwidth management, the computer network can work optimally. Campuses, agencies or companies generally require bandwidth management with a proxy router, the goal is to help overcome the density of traffic that can interfere with computer network connections, where when the network is down or the computer network is experiencing problems due to the absence of an even distribution of bandwidth in each user, by because of that there needs to be management in the distribution of the amount of bandwidth, aiming to get the right bandwidth capacity for each user. The bandwidth capacity will later be distributed to each user in accordance with their priorities in using the internet so that the amount of available bandwidth capacity can be optimized. QOS (Quality of services) or better known as bandwidth management. This application is carried out in several stages, namely, designing computer networks, implementation and finally testing which is marked by the availability of a more stable computer network.
\end{abstract}

Keywords : Information Technology, Bandwidth Management, Quality of services (QOS.

\begin{abstract}
Abstrak - Seiring perkembangan teknologi informasi saat ini, maka perkembangan jaringan komputer juga ikut berkembang, dengan adanya prangkat dan aplikasi untuk manajemen bandwidth, maka jaringan komputer dapat bekerja secara optimal. Kampus-kampus, instansi atau perusahaan pada umumnya memerlukankan manajement bandwidth dengan router mikrotik, tujuannya untuk membantu mengatasi padatnya trafik yang dapat menggangu koneksi jaringan komputer, dimana ketika jaringan down atau jaringan komputer mengalami masalah yang diakibatkan belum adanya pembagian bandwidth yang merata disetiap user, oleh karena itu perlu adanya pengelolahan dalam pembagian jumlah bandwidth, bertujuan untuk mendapatkan kapasitas bandwidth yang tepat bagi setiap usernya. Kapasitas bandwidth tersebut nantinya akan dibagikan kepada setiap user sesuai dengan prioritasnya dalam penggunaan internet sehingga besarnya kapasitas bandwidth yang telah tersedia dapat dioptimalkan. QOS (Quality of services) atau lebih dikenal dengan manajemen bandwidth. Penerapan ini dilakukan dengan beberapa tahapan yaitu, perancangan jaringan komputer, implementasi dan terakhir adalah pengujian yang ditandai dengan ketersediaan jaringan komputer yang lebih stabil.
\end{abstract}

Kata kunci : Teknologi Informasi, Manajemen Bandwidth, Quality of services (QOS).

\section{A. PENDAHULUAN}

Perkembangan dibidang teknologi informasi pada saat ini berkembang sangat pesat, baik perkembangan dibidang perangkat lunak maupun perangkat keras, seiring dengan kebutuhan manusia di zaman modern ini. Salah satu teknologi informasi yaitu internet telah membawa dampak yang begitu berarti pada berbagai aspek kehidupan manusia. Pada Kampus Universitas Bina Sarana Informatika memiliki infrastruktur jaringan komputer untuk memenuhi kebutuhan akses internet baik untuk karyawan, staf pengajar, maupun untuk mahasiswa.

Oleh karna itu penulis tertarik untuk menganalisa jaringan komputer yang ada di kampus tersebut. Penelitian yang dilakukan bertujuan untuk optimalisasi jaringan dengan router mikrotik studi kasus Kampus UBSI Tangerang. Kesimpulan yang didapat adalah mengoptimalkan sistem jaringan yang ada dengan Router Mikrotik, dengan melakukan penambahan sistem management jaringan dengan lebih kompleks dan optimal, baik dari segi firewall maupun management bandwith untuk client pada jaringan komputer yang ada pada Kampus UBSI Tangerang.

Penelitian penerapan ini dilakukan bertujuan untuk :

1. Optimalisasi Penggunaan jaringan komputer. 
2. Untuk mengetahui penyebab atau faktor mempengaruhi penggunaan jaringan komputer.

3. Untuk mengetahui bagaimana model atau metode penggunaan jaringan komputer.

4. Memberikan saran atau masukan untuk pengguna jaringan komputer.

\section{B. TINJAUAN PUSTAKA}

1. Jaringan Komputer

(Kadir \& Triwahyuni, 2013) "Jaringan komputer adalah kumpulan komputer suatu kesatuan system".

\section{Topologi}

(Soepomo, 2014) "Topologi dalam jaringan mengandung dua pengertian dilihat dari sisi pengkabelan dan dari sisi aliran data".

\section{Internet}

(Wonkar et al., 2015) internet adalah gabungan dari berbagai LAN dan WAN yang berada di seluruh dunia secara global.

\section{Manajemen Bandwith atau Quality of services (QOS) \\ Merupakan sebuah metode atau cara} konfigurasi yang digunakan untuk memenuhi kebutuhan pada jaringan komputer.

(Pamungkas, 2016) Bandwidth merupakan kapasitas atau daya tampung kabel Ethernet agar dapat dilewati trafik paket data dalam jumlah tertentu.

\section{Perencanaan Penerapan}

(Triyono \& Dharma, 2018) menyarankan langkah-langkah dalam sebuah perencanaan penerapan meliputi: Mengidentifikasi masalah, merumuskan masalah, menganalisis masalah dan merumuskan tindakan, membuat rencana, melaksanakan tindakan, mengamatinya, mengolah, menafsirkan data penerapan, dan melaporkan hasil penerapan.

(Stringer, 2007) Meskipun demikian ada beberapa tahapan bisa dilalui dalam penerapan yaitu : tahap perencanaan, tahap pelaksanaan, pengamatan (observation), dan refleksi (reflection).

(Stringer, 2007) Kemudian keempat langkah tersebut dikemukakan oleh Lewin diatas, oleh Stringer : Perencanaan (planning), Pelaksanaan (implementing) dan Penilaian (evaluation)

\section{METODE PENELITIAN}

Dalam penelitian penerapan ini dilakukan empat tahapan proses yang dilakukan di kampus UBSI Tangerang sebagai tempat studi kasus.
Ke empat tahapan ini dilakukan secara berurutan dan berkaitan antara tahapan satu dengan tahapan yang lain :

\section{Pencarian data}

Pencarian data dilakukan dengan 3 proses yang pertama Mengamati jaringan Internet yang ada di kampus UBSI Tangerang, serta kondisi layanan Internet yang saat ini di gunakan di kampus. Selanjutnya merancang sistem manajement bandwidth. Proses yang kedua adalah degan wawancara Adapun proses wawancara berkaitan dengan rancangan jaringan di kampus, agar proses analisis jaringan sesuai dengan tujuan yang diinginkan. yang terahir mengunakan metode kepustakaan yaitu dengan mencari referensi dari sumber bacaan.

\section{Analisis jaringan}

Analisis jaringan dilakukan untuk melihat rancangan jaringan yang ada saat ini. Dalam analisis ini akan dilihat bentuk topologi jaringan yang digunakan dan kebiijakan kebijakan atau pengaturan yang dilakuan pada jaringan kampus.

\section{Perancangan}

Perancangan manajement bandwidth dilakukan dengan hasil dari analisis yang dilakukan ditahapan sebelumnya. Perancangan ini menghasilkan skema yang cocok untuk manajement bandwidth yang diterapakan apakah hannya pada jalur tertentu atau keseluruhan dari jalur yang ada.

\section{Pengujian}

Tahap pengujian dilakukan setelah perancangan berhasil dilakukan pengujian terhadap sistem manajement bandwidth yang sudah dilakukan. Pengujian meliputi pengujian keberhasilan sistem utama dimana manajement bandwidth sendiriakan berhasil jika pengujian yang lain berkaitan dengan keseimbangan koneksi dan ip yang digunakan.

\section{HASIL DAN PEMBAHASAN}

Pada penelitian penerapan ini penulis mengimplementasi manajemen bandwith pada universitas bina sarana informatika kampus tangerang.

Berdasarkan analisa jaringan koneksi ke internet kurang stabil dan dapat mengakibatkan penyelesaian pekerjaan yang tertunda dan kerugian materi akibat terlambatnya pekerjaan. Hal ini menyebabkan kinerja karyawan tidak dapat optimal

Oleh karena itu, penulis menerapkan manajemen bandwith dalam pengelolahan 
pembagian jumlah bandwidth dan merata bagi setiap user.

Gambar 1 berikut ini merupakan topologi penelitian yang akan penulis terapkan.

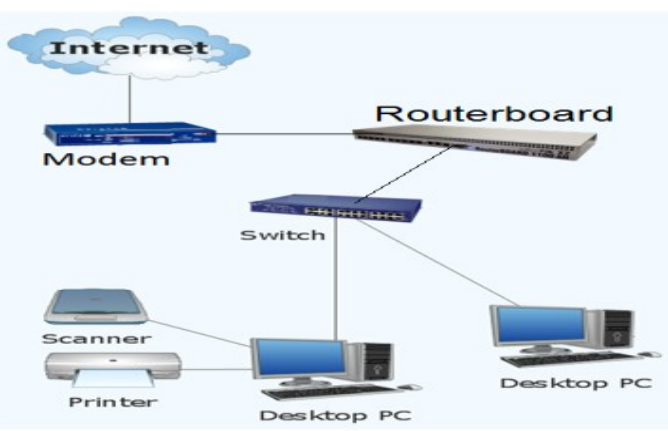

Gambar 1. Topologi penelitian yang diterapkan

Tahapan-tahapan untuk iplementasi yang penulis gunakan sebagaimana tampak pada gambar 2 .

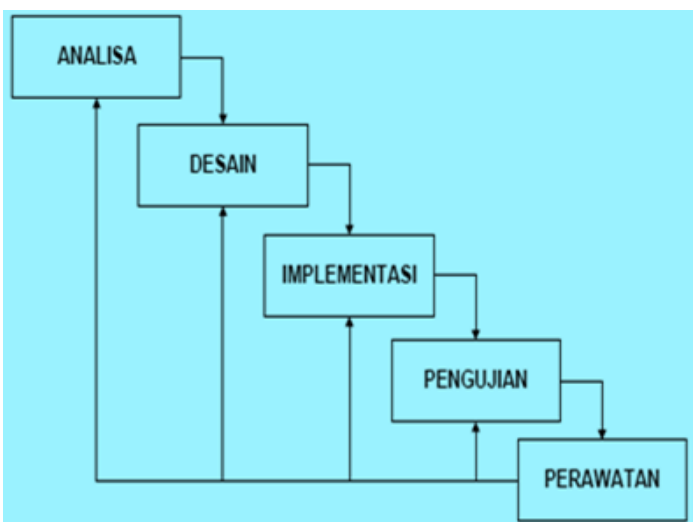

Gambar 2. Tahapan-tahapan untuk penerapan

Konfigurasi Manajemen Bandwidth :

Metode Pembagian Bandwidth

Hampir sama seperti firewall, posisi manajemen bandwidth berada ditengah, bisa berisafat bridge ataupun routing.

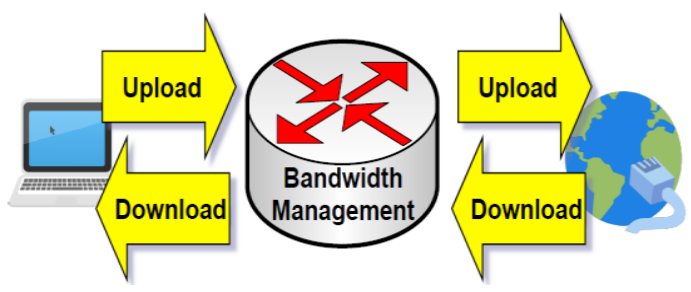

Gambar 3. Metode Bandwidth Manajemen
Implemetasi atau konfigurasi Simple Queue

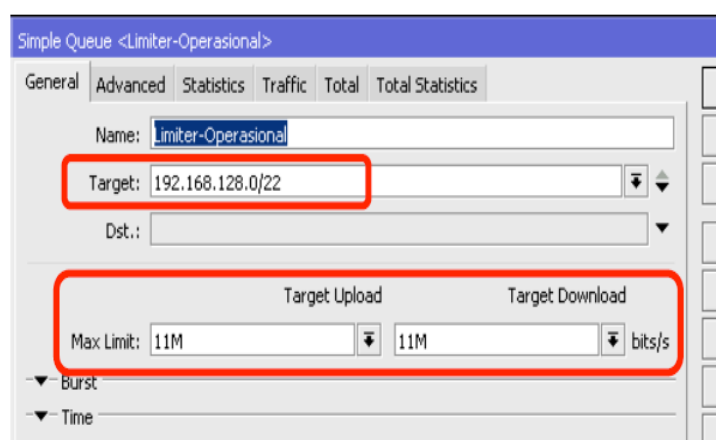

Gambar 4. Implemetasi Simple Queue

\section{Contoh Kasus 1}

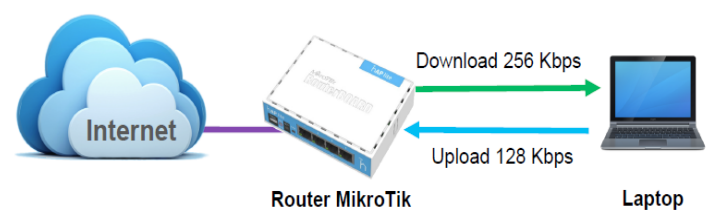

Gambar 5. Skema studi kasus 1

\section{Rule Simple Queue}

Target diisi dengan IP client yang akan kita limit pengaturannya, dan kemudian tentukan max-limit untuk melimit penggunaan bandwidth yang kita inginkan.

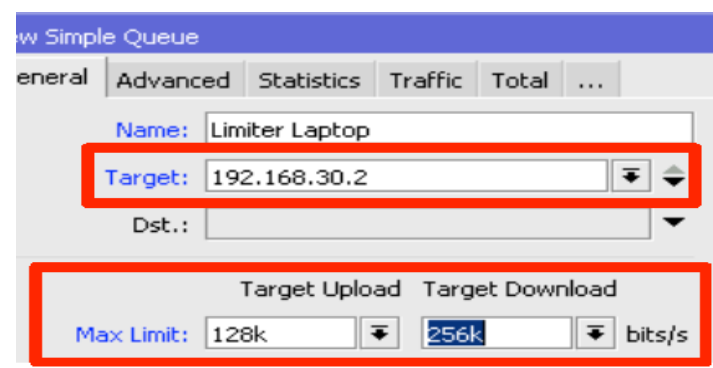

Gambar 6. Rule Simple Queue

\section{Contoh Kasus 2}

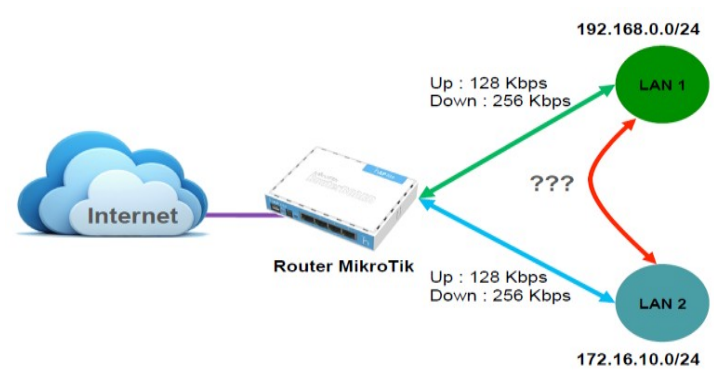

Gambar 7. Skema studi kasus 2 


\section{Parameter Destination}

Parameter Destination digunakan untuk menentukan limitasi ke tujuan tertentu, studi kasus ini Dst diisikan dengan IP segmen LAN tujuan.

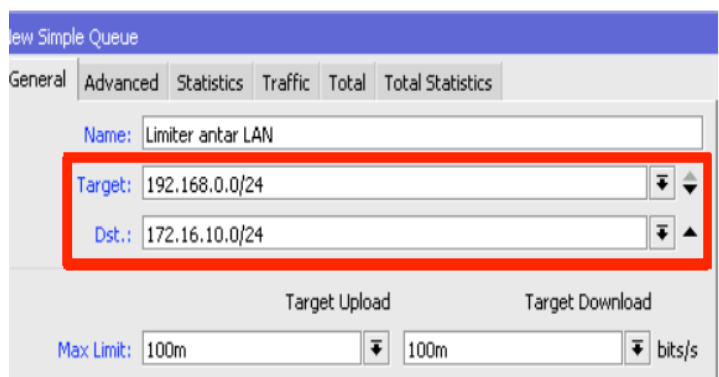

Gambar 8. Parameter

\section{Urutan Rule Simple Queue}

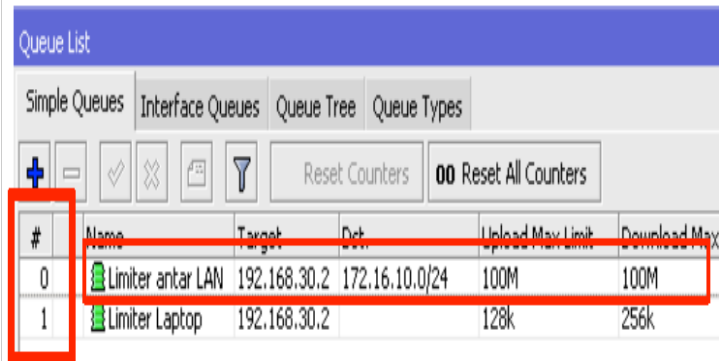

\section{Gambar 9. Urutan Rule}

\section{Contoh Kasus 3}

Langkah pertama yaitu melimitasi maksimal pada client untuk target upload dan target download max-limit dengan drop down menu atau ditulis manual. Satuan bit per second (bps)

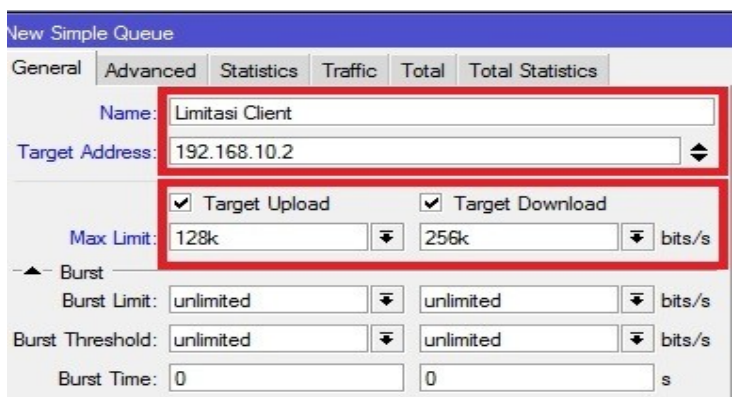

\section{Gambar 10. Konfigurasi Limitasi Client}

Dengan konfigurasi pada gambar 10 maka pada setiap user yang sudah terhubung akan mendapatkan kecepatan yang lebih stabil dan merata.

\section{Pembagian Bandwidth Share Contoh Kasus 4}

Kita akan melakukan pengaturan bandwidth untuk tiga client.

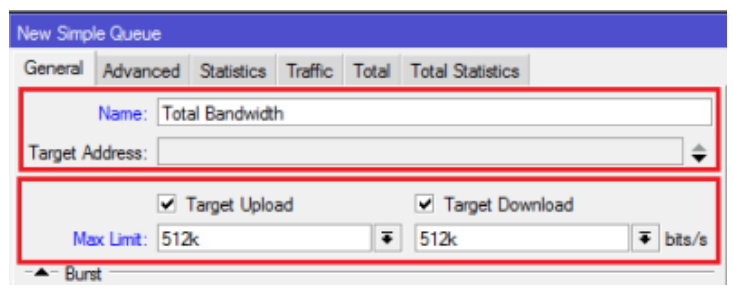

\section{Gambar 11. Konfigurasi Total Bandwith}

Berikutnya kita akan menentukan limitasi per user dengan melakukan konfigurasi childqueue. Ulangi untuk memberikan limitasi pada client yang lain.

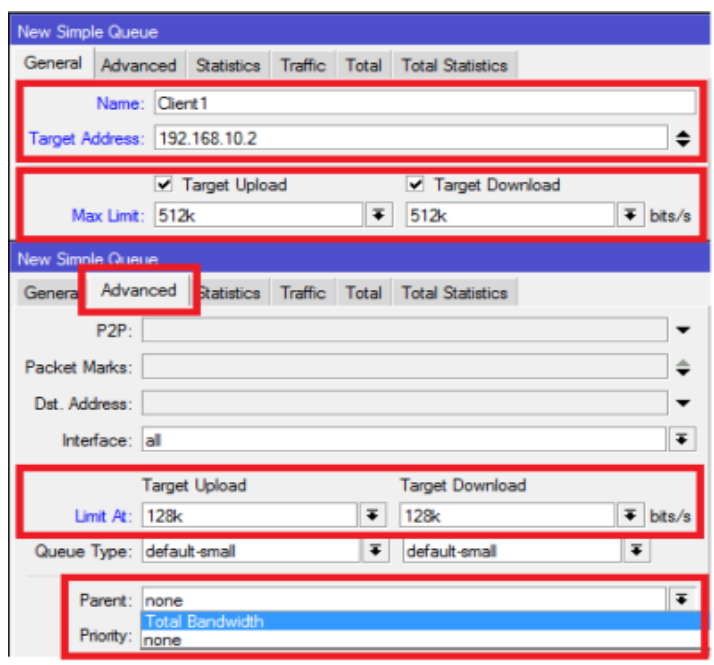

\section{Gambar 12. Konfigurasi Limitasi per user}

Berikutnya pengetesan atau ujicoba dengan melakukan download dari sisi user.

\begin{tabular}{|c|c|c|c|c|c|c|c|c|}
\hline \multicolumn{9}{|c|}{ Queve Lat } \\
\hline \multicolumn{2}{|c|}{ Simple Queves } & \multicolumn{2}{|c|}{ Inteflace Quevas } & \multicolumn{4}{|c|}{ Queus Tree Queus Types } & \\
\hline 中 & $=v x$ & $\square$ & 8 & $00 \mathrm{~F}$ & Reset Courten & 00 Reset & Counters & \\
\hline$\#$ & \multirow{2}{*}{ Name } & \multicolumn{3}{|c|}{ 1. Targes Addes: } & Tx Mrs Limt & $T x \operatorname{Lim} t A t$ & Pareent & $\mathrm{Tx}$ \\
\hline 0 & \multirow{2}{*}{\multicolumn{2}{|c|}{ Bete Total Bandwidth }} & & & $512 k$ & unimited & fone & $513.8 \mathrm{ktos}$ \\
\hline 1 & & & \multicolumn{2}{|c|}{192.168 .10 .1} & $512 k$ & $128 k$ & Total Bandwith & $513.5 \mathrm{kbos}$ \\
\hline 2 & \multicolumn{2}{|l|}{ SClert2 } & \multicolumn{2}{|c|}{192.158 .102} & $512 k$ & $12 \mathrm{~kg}$ & Total Bandwinth & Obps \\
\hline 3 & \multicolumn{2}{|l|}{ - } & \multicolumn{2}{|c|}{192.168 .103} & $512 k$ & $12 \%$ & Total Bandwith & Obos \\
\hline
\end{tabular}

\section{Gambar 13. Ujicoba download satu user}

Kondisi 1 : Pada gambar 13 akan memenuhi Limit-at user. Karena user lain tidak aktif. 


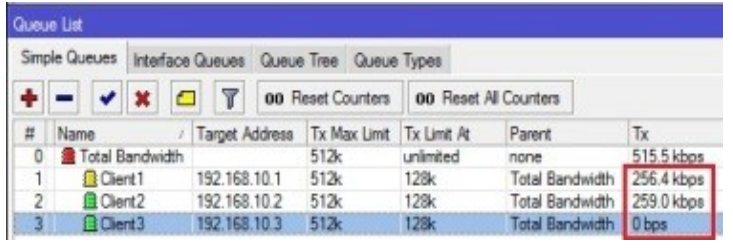

\section{Gambar 14. Ujicoba download dua user}

Kondisi 2 : Pada gambar 14 menggambarkan ketika hanya dua user yang menggunakan bandwidth.

Akan memberikan limit-at semua user terlebih dahulu.

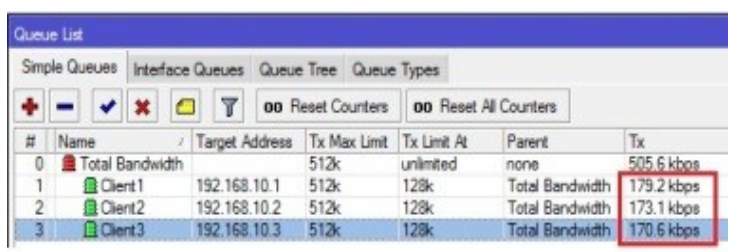

\section{Gambar 15. Ujicoba download tiga user}

Kondisi 3 : Pada gambar 15 akan memenuhi Limit-at tiap user lebih dulu, sehingga merata.

\section{Contoh Kasus 5}

Client 1 adalah VVIP user, maka bisa diberikan Priority 1 (tertinggi).

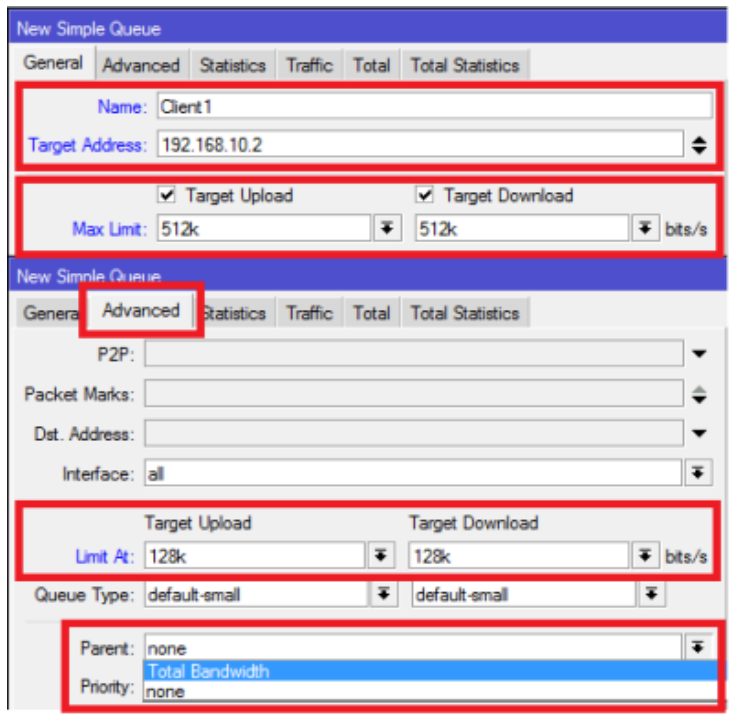

\section{Gambar 16. Konfigurasi Limitasi user}

Jika kita menerapkan priority perhitungan pada gambar 16 pembagian bandwidth hampir sama dengan sebelumnya.

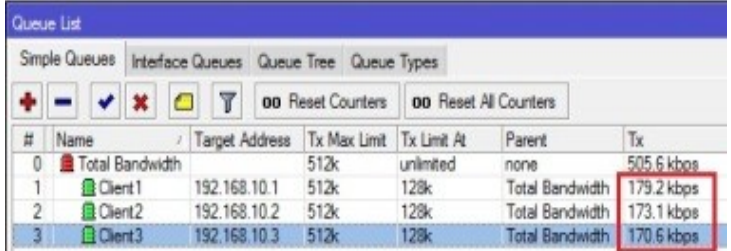

\section{Gambar 17. Ujicoba download}

Client 1 : mempunyai priority tertinggi maka router akan mencoba memberikan bandwidth sampai batas Max-Limit.

\section{Bypass Traffic Lokal}

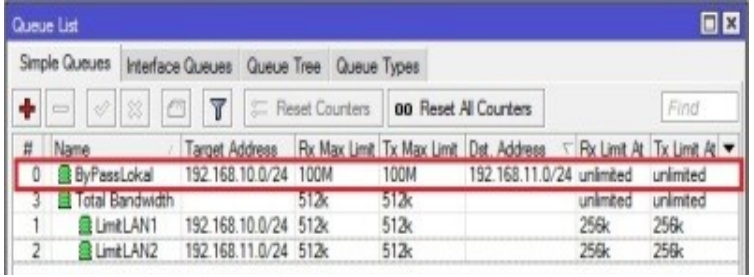

\section{Gambar 18. Bypas Trafic}

Rule Simple Queue pada gambar 18 dibaca dari urutan teratas (no. 0)

\section{Pengujian Management Bandwidth}

Pengujian Management Bandwidth yang penulis lakukan dengan menggunakan tiga unit komputer client yang digunakan sebagai parameter keberhasilan. Masingmasing komputer yang sudah terhubung ke jaringan dan sudah terkoneksi ke internet, akan dicoba untuk melakukan proses mengunduh sejumlah data dari internet dengan ukuran yang telah ditentukan oleh peneliti. Hal ini dilakukan untuk melihat apakah Router Mikrotik dapat membagi rata bandwidth yang tersedia atau tidak sesuai dengan management bandwidth yang telah diterapkan. Pada pengujian ini, data pengujian bisa dilihat pada gambar 19 berikut.

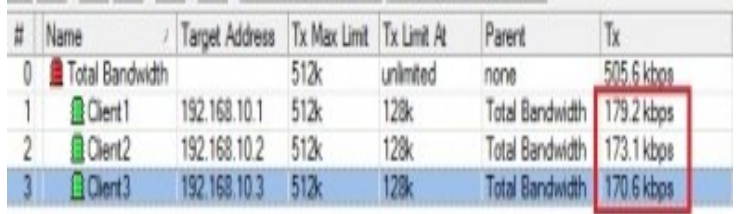

\section{Gambar 19. Pengujian Management Bandwidth}

Dari hasil pengujian pada gambar 19 yang dilakukan terhadap implementasi Management Bandwidth menggunakan Mikrotik Routerboard, didapatkan hasil yang cukup memuaskan. Hal ini terlihat pada gambar 19 , 
bandwidth yang diperoleh oleh ketiga komputer, pengujian memiliki jumlah bandwidth rata-rata yang hampir sama yaitu pada kisaran angka 170 kbps, yang artinya bandwidth terbagi dengan rata dan stabil.

\section{E. KESIMPULAN}

Pada penelitian ini penulis menggunakan metode simple queue yang fungsi adalah untuk pembagian bandwidth pada masing-masing client komputer yang terhubung dalam jaringan komputer.

Setelah penulis melakukan analisa pada penerapan penggunaan manajemen bandwidth, maka dapat disimpulkan :

1. Dengan melakukan pengelolaan bandwidth Simple Queue kebutuhannya, tanpa adanya pemakaian bandwidth yang terlalu besar oleh salah satu pengguna saja.

2. Dengan melakukan perhitungan kapasitas bandwidth dibagi dengan jumlah pengguna yang ada maka setiap pengguna mendapatkan batas terendah bandwidth dan batas terbesar.

3. Semua perangkat atau device dapat menggunakan internet dengan baik dan stabil.

4. Semua bagian unit atau client memperoleh bandwidth berdasarkan kebutuhan masing-masing.

\section{DAFTAR PUSTAKA}

Kadir, A., \& Triwahyuni, T. (2013). Pengantar Teknologi Informasi Edisi Revisi (p. 2). p. 2. https://doi.org/10.13140/2.1.4734.7840

Pamungkas, C. A. (2016). Manajemen bandwith menggunakan mikrotik routerboard di politeknik indonusa surakarta. 1, 3-8.

Soepomo, P. (2014). 210977-Analisis-DanOptimalisasi-Jaringan-Mengg[1]. 1370-1378.

Stringer, E. (2007). Action Research 3rd. ed. In Action Research.

Triyono, T., \& Dharma, U. W. (2018). Penelitian Tindakan Kelas: Apa Dan Bagaimana Melaksanakannya? (March), 1-17.

https://doi.org/10.13140/RG.2.2.26385.12 649

Wonkar, S., Sinsuw, A., \& Najian, X. (2015). Analisa Implementasi Jaringan.., $E$ Journal Teknik Komputer, 4(6), 62-68. Retrieved from https://ejournal.unsrat.ac.id/index.php/ele kdankom/article/view/10400/9986 